\title{
Será Doença de Fabry? Abordagem Diagnóstica e de Seguimento
}

\section{Is it Fabry Disease? Diagnostic and Follow-Up Approach}

Idalina BEIRÃO $\rrbracket^{1,2}$, Ana CABRITA ${ }^{3}$, Márcia TORRES ${ }^{4}$, Fernando SILVA ${ }^{5}$, Patrício AGUIAR ${ }^{6}$, Ana Marta GOMES $^{7}$

Acta Med Port 2016 Feb;29(2):85-87 - http://dx.doi.org/10.20344/amp.6468

Palavras-chave: Doença de Fabry/diagnóstico; Doença de Fabry/tratamento.

Keywords: Fabry Disease/diagnosis; Fabry Disease/therapy.

A doença de Anderson-Fabry (DAF) é uma doença sistémica de sobrecarga lisossomal causada por mutações patogénicas do gene GLA (cromossoma $X$ ) que condicionam diminuição ou ausência a-galactosidase A e acumulação de globotriaosilceramida (Gb3) e outros glicoesfingolípidos nos lisossomas, particularmente das células endoteliais, neuronais, cardíacas e renais que levam à fibrose e lesão irreversível de órgão. ${ }^{1}$

Estão descritas mais de 550 mutações do gene GLA e $3 \%$ - $10 \%$ são mutações de novo. ${ }^{2}$ Existe heterogeneidade fenotípica intrafamiliar e o fenótipo depende da atividade residual da $\alpha$-galactosidase $A$ e de outros fatores genéticos, epigenéticos e ambientais, ${ }^{1}$ Não existe correlação genótipo-fenótipo que auxilie na estratificação do risco clínico associado. ${ }^{1}$

A prevalência da DAF oscila entre 1:40 000 para 1:117 000 nos Estados Unidos da América e na Austrália, ${ }^{2}$ maioritariamente doentes caucasianos. Rastreios neonatais efetuados em Itália, Taiwan e Missouri revelaram prevalências de mutações patogénicas no gene GLA entre 1:1 250 e 1:3 100 (na maioria associadas a fenótipos atenuados). ${ }^{2,3}$

Em Portugal, foram diagnosticados, até ao final de 2014, 133 doentes com DAF na Unidade de Bioquímica Genética do Centro de Genética Médica Jacinto Magalhães, oriundos de todo o país (dados não publicados). Nessa data, 48 doentes encontravam-se em terapêutica de substituição enzimática (TSE) segundo informação da Comissão Coordenadora do Tratamento de Doenças Lisossomais de Sobrecarga (Paula Garcia. Lisossomal diseases, the portuguese landscape. $1^{\text {st }}$ Fabry lberia KOL meeting).

A apresentação clássica da doença ocorre geralmente em homens hemizigotos na infância/adolescência. As muIheres heterozigotas, embora possam ser tão gravemente afetadas como os homens, tendem a apresentar a doença mais tardia e mais insidiosa, facto provavelmente relacionado com a inativação aleatória do cromossoma X. ${ }^{1}$
$\mathrm{Na}$ idade adulta, predominam as manifestações cardíacas, cerebrovasculares e renais. ${ }^{1}$ Nos fenótipos atenuados, a apresentação é mais tardia e envolve predominantemente um órgão (fenótipos cardíaco, renal ou cerebrovascular). ${ }^{1}$

Na forma clássica surgem, na infância/adolescência, angioqueratomas, acroparestesias, sintomas gastrointestinais (dor abdominal pós-prandial, saciedade precoce, distensão abdominal, diarreia, náuseas e vómitos), intolerância ao calor, frio e exercício físico, hipotensão ortostática e hipo ou hiperhidrose, associados a disfunção de fibras de pequeno diâmetro do sistema nervoso periférico e autonómico. ${ }^{1,2}$ À dor neuropática podem sobrepor-se as crises álgicas de Fabry induzidas pelo exercício, alterações de temperatura, febre, fadiga ou stress ${ }^{1}$ por vezes associadas a artralgias, febre ou elevação da velocidade de sedimentação. ${ }^{4}$ Estas situações são frequentemente diagnosticadas como reumatismo, infeções víricas, dores de crescimento, problemas ósseos, dor psicogénica ou gastrointestinal não específica e intoxicação alimentar. ${ }^{5}$ A córnea verticillata, que raramente afeta a acuidade visual, está presente em mais de $90 \%$ dos doentes. ${ }^{1}$

No rim, a acumulação progressiva de Gb3 nas células renais manifesta-se inicialmente como isostenúria, poliúria $^{1,2}$ e eventualmente síndrome de Fanconi com aminoacidúria, glicosúria e acidose tubular. $\mathrm{Na} 2^{\mathrm{a}}-3^{\mathrm{a}}$ década de vida surge proteinúria e declínio progressivo da taxa de filtração glomerular (TFG). ${ }^{1}$ Nos homens, a DRC é comparável à nefropatia diabética, com uma diminuição média da TFG de aproximadamente $12 \mathrm{~mL} / \mathrm{min} / \mathrm{ano}$ e DRC terminal na $4^{\mathrm{a}}$ - $5^{\mathrm{a}}$ década de vida. ${ }^{1,2}$

As manifestações cardíacas, presentes em $40 \%-60 \%$ dos doentes, ${ }^{2}$ associam-se a depósitos de Gb3 (1\% da massa miocárdica) e a inflamação e desregulação neuro-humoral. ${ }^{1,6}$ Pode ocorrer hipertrofia ventricular esquerda (HVE), insuficiência valvular aórtica e mitral, alterações de condução, doença coronária de predomínio microvascular,

\footnotetext{
1. Serviço de Nefrologia. Centro Hospitalar do Porto. Porto. Portugal.

2. ICBAS, Instituto de Ciências Biomédicas Abel Salazar. Porto. Portugal.

3. Serviço de Nefrologia. Centro Hospitalar do Algarve. Faro. Portugal.

4. Serviço de Cardiologia. Centro Hospitalar do Médio Ave. Santo Tirso. Portugal.

5. Serviço de Neurologia. Centro Hospitalar Universitário de Coimbra. Coimbra. Portugal.

6. Serviço de Medicina 1. Hospital de Santa Maria. Centro Hospitalar Lisboa Norte. Lisboa. Portugal.

7. Serviço de Nefrologia. Centro Hospitalar de Vila Nova de Gaia/Espinho. Vila Nova de Gaia. Portugal.

$\square$ Autor correspondente: Idalina Beirão. idalina.m.b@gmail.com

Recebido: 31 de março de 2015 - Aceite: 17 de agosto de 2015 | Copyright $\odot$ Ordem dos Médicos 2016
} 
dilatação da raiz da aorta e hipertrofia do ventrículo direito. ${ }^{2}$ Estas alterações podem manifestar-se por angor, dispneia, palpitações ou síncope. ${ }^{2}$ As manifestações cardíacas podem predominar - fenótipo atenuado cardíaco, frequente na mulher. ${ }^{6}$ A HVE, presente em $50 \%$ dos homens e $33 \%$ das mulheres, ${ }^{6}$ é geralmente concêntrica, mas pode ser assimétrica (hipertrofia do septo e adelgaçamento da parede posterior) e ocasionalmente com obstrução no trato de

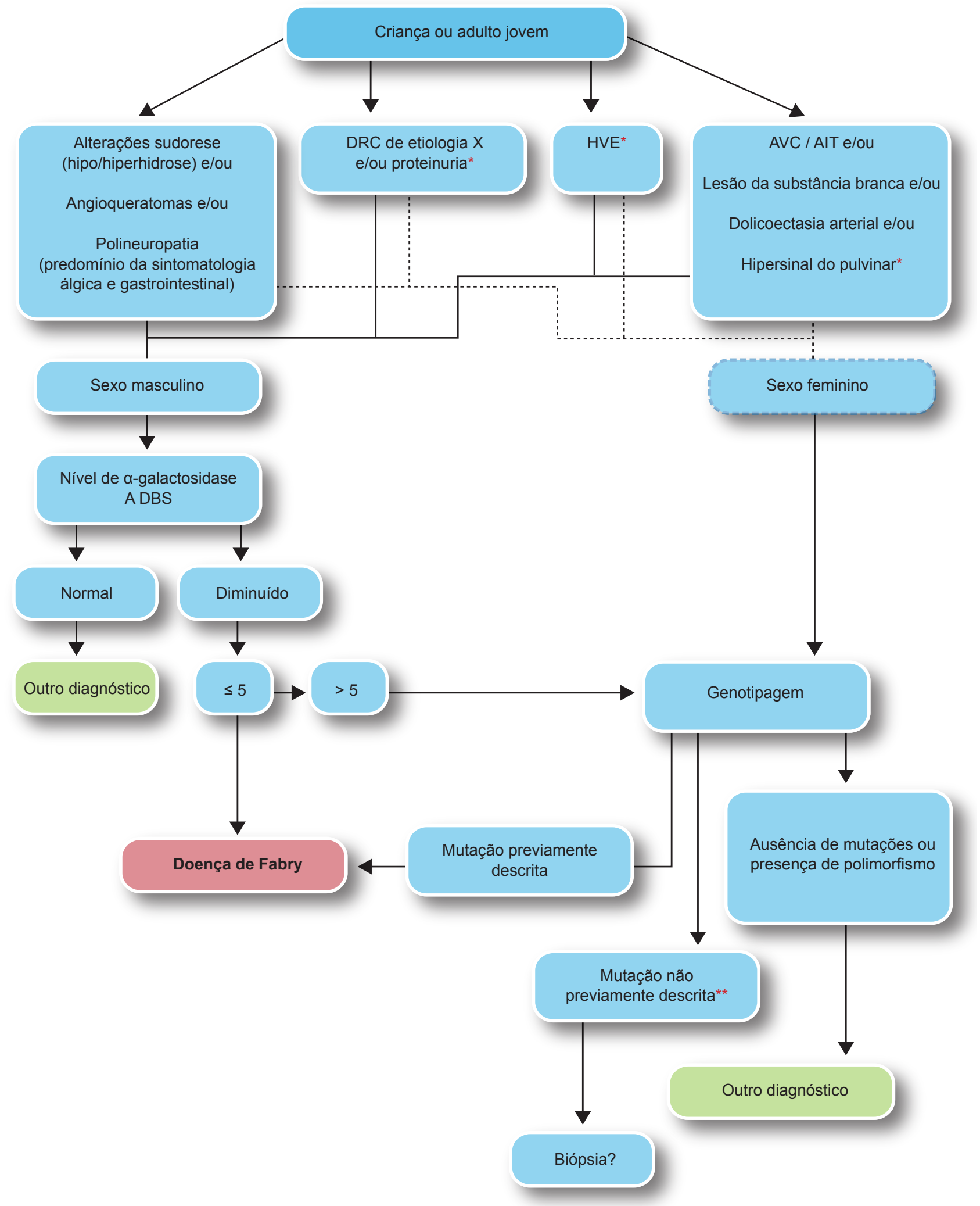

Figura 1 - Algoritmo de diagnóstico da doença de Fabry

* Considerar também adultos.

** Reavaliação clínica, análise de pedigree, determinação de biomarcadores, expressão da mutação in vitro e confirmação histológica de depósitos de Gb3. 
saída do ventrículo esquerdo. ${ }^{2,6} \mathrm{O}$ ecocardiograma com avaliação do strain/strain rate e a ressonância magnética (RM) são importantes no estudo da HVE. ${ }^{2}$ A RM cardíaca permite diagnosticar formas localizadas de hipertrofia e a sua exata distribuição, não identificáveis por ecocardiografia. $^{2}$ No eletrocardiograma, observa-se inicialmente intervalo PR curto e posteriormente critérios de voltagem de HVE, alterações da repolarização de sobrecarga/isquemia, prolongamento do intervalo PR, bloqueio aurículo-ventricular de $2^{\circ}$ e $3^{\circ}$ grau e disritmias ventriculares..$^{1,2,6}$

As complicações cerebrovasculares da DAF incluem os acidentes isquémicos transitórios, os acidentes vasculares cerebrais (AVC), isquémico e hemorrágico, e as lesões da substância branca. ${ }^{1,2} \mathrm{O}$ padrão típico de lesão vascular é a lesão de pequenos vasos ${ }^{2}$ com predileção pelo território vertebro-basilar. ${ }^{2} \mathrm{O}$ AVC afeta $6,9 \%$ dos homens (idade média - 39 anos) e $4,3 \%$ dos doentes com DAF e pode ser a primeira manifestação da doença (fenótipo atenuado cerebrovascular). ${ }^{2}$

A confirmação do diagnóstico pode efetuar-se pela determinação da atividade da $\alpha$-galactosidade $A$ e/ou pela sequenciação do gene GLA (Fig. 1). No homem, a determinação da atividade da a-galactosidade A (plasma, nos leucócitos e em testes de 'gota seca' - dried blood spot DBS) constitui o exame de primeira escolha na avaliação dos doentes suspeitos. ${ }^{7}$ Nos homens com fenótipo clássico uma atividade da $\alpha$-galactosidade $A<5 \%$ do normal é diagnóstica mas, nos homens com fenótipo atenuado, a atividade enzimática residual pode ser considerável e, nestes casos é necessária a sequenciação do gene GLA para diagnóstico definitivo. ${ }^{7}$

As mulheres (heterozigóticas) apresentam níveis significativos de atividade enzimática pelo que é obrigatória a sequenciação do gene GLA para despiste de mutações. ${ }^{2}$

A biópsia renal é importante para confirmar o diagnós-

\section{REFERÊNCIAS}

1. Eng CM, Germain DP, Banikazemia M, Warnock D, Wanner C, Hopkin $\mathrm{RJ}$, et al. Anderson-Fabry disease: guidelines for the evaluation and management of multi-organ system involvement. Gent Med. 2006;9:539-48.

2. Germain DP. Fabry disease. Orphanet J Rare Dis. 2010;5:30.

3. Hopkins PV, Campbell C, Klug T, Rogers S, Raburn-Miller J, Kiesling J. Lysosomal storage disorder screening implementation: findings from the first six months of full population pilot testing in Missouri. J Pediatr. 2015;166:172-7.

4. Lacomis D, Roeske-Anderson L, Mathie L. Neuropathy and Fabry's disease. Muscle Nerve. 2005;31:102-7.

5. Marchesoni CL, Roa N, Pardal AM, Neuman P, Caceres G, Martinez P, et al. Misdiagnosis in Fabry disease. J Pediatr. 2010;156:828-31.

6. Yousef Z, Elliot PM, Cecchi F, Escoubet B, Linhart A, Monserrat L, et al. Left ventricular hypertrophy in Fabry disease: a practical approach to tico nos casos em que a patogenicidade de uma mutação não é conhecida, para excluir outras patologias renais nas apresentações atípicas da doença e para avaliar a gravidade do envolvimento renal. A vacuolização dos podócitos, das células epiteliais parietais e das células tubulares são achados histológicos característicos na microscopia ótica. ${ }^{2}$

A biópsia miocárdica está limitada aos casos em que a atividade de $\alpha$-galactosidase é residual nos homens e a patogenicidade da mutação genética não é conhecida, não existindo outra forma de comprovar a etiologia da HVE. ${ }^{2}$

As manifestações clínicas inespecíficas e comuns a outras patologias mais frequentes (fenocópias) condicionam o atraso no diagnóstico, em média de 15 anos em ambos os sexos, ${ }^{2}$ o que valeu à DAF o título 'o novo grande impostor', anteriormente reservado à sífilis. ${ }^{8}$

A DAF não tratada reduz a sobrevida em cerca de 20 anos nos homens e 10 anos nas mulheres ${ }^{2}$. Com o advento da diálise, as complicações cardiovasculares tornaram-se a principal causa de morte. ${ }^{9}$ A TSE já disponível, está, de um modo geral, indicada nos homens com o fenótipo clássico, nas mulheres e fenótipos atípicos sintomáticos e nos doentes com DRC terminal. ${ }^{10}$ A TSE atrasa a progressão da doença renal, reduz a massa ventricular esquerda e meIhora a dor neuropática e a qualidade de vida ${ }^{2}$ pelo que a sua instituição deve ser considerada o mais precocemente possivel.

\section{CONFLITOS DE INTERESSE}

Os autores declaram não existir quaisquer conflitos de interesse.

\section{FONTES DE FINANCIAMENTO}

Este trabalho foi realizado com apoio financeiro da Sanofi - Produtos Farmacêuticos, Lda., que não foi condicional à obtenção de nenhum tipo específico de resultados. diagnosis. Eur Heart J. 2013;34:802-8.

7. Gal A, Hughes DA, Winchester B. Toward a consensus in the laboratory diagnostics of Fabry Disease - recommendations of an European expert group. J Inherit Metab Dis. 2011;34:509-14.

8. Farge D, Nadler S, Wolfe LS, Barre P, Jothy S. Diagnostic value of Kidney biopsy in heterozygous Fabry's disease. Arch Pathol Lab Med. 1985;109:85

9. Branton MH, Schiffmann R, Sabnis SG, Murray GJ, Quirk JM, Altarescu $G$, et al. Natural history of Fabry renal disease: influence of alphagalactosidase. A activity and genetic mutations on clinical course. Medicine. 2002;81:122

10. Rombach SM, Hollak CE, Linthorst GE, Dijkgraaf MG. Costeffectiveness of enzyme replacement for Fabry disease. Orphanet $J$ Rare Dis. 2013:19;8:29. 